\title{
DESCRIPTION OF A NEW SPECIES AND THE KARYOTYPE OF THE CAVERNICOLOUS MILLIPEDE PSEUDONANNOLENE SILVESTRI AND THE KARYOTYPE OF PSEUDONANNOLENE STRINATTI MAURIÈS (DIPLOPODA, PSEUDONANNOLENIDA, PSEUDONANNOLENIDAE)
}

\author{
Carmem Silvia Fontanetti ${ }^{1}$
}

\begin{abstract}
Pseudonannolene tocaiensis, sp.n. is described from Brazil, São Paulo, Itirapina. The karyotypes of $P$. tocaiensis, sp.n. and $P$. strinatti Mauriès, 1974 are also presented, both species are found in cave environments. $P$. tocaiensis has $2 \mathrm{n}=20, \mathrm{XY}$ and $P$. strinatti, $2 \mathrm{n}=16$; it was not possible to observe the sex determination mechanism in the latter.

KEY WORDS. Diplopoda, Pseudonannolene, cave millipedes, cytogenetic, millipedes
\end{abstract}

The Diplopoda class is an interesting material for cytogenetic research because it has been little studied from this point of view; up to date, only about 75 of a total of 10.500 described species have been studied throughouth the world. Also, few researchers have studied the taxonomy of the diplopods species. In Brazil, only Dr. Otto Shubart has studied the country's fauna. The group need a taxonomic revision, since various new species, doubtful genus, etc. have frequently been found in the carried out collects.

This fact is apparent mainly in Pseudonannolene Silvestri, 1895. This genus, which is made up of about 35 described species found in the neotropical region, is the only genus of the Pseudonannolenidae family found in Brazil.

Millipedes of Pseudonannolene are common in the cave diplopod fauna. Although SCHUBART $(1946,1956)$, in his works carried out in the caves of Iporanga, did not mention any Pseudonannolene species, MAURIĖs (1974) described $P$. strinatii for the Areias cave, located in the same region. According to collects made in caves in São Paulo, Paraná, Minas Gerais, Bahia and Goiás this species is commonly found. Other species, new to science, were also found.

The present work presents a description of a new species from the State of São Paulo, its karyotype and the karyotype of another cave species already described, $P$. strinatti.

1) Departamento de Biologia, Instituto de Biociências, Universidade Estadual Paulista. Avenida 24 A 1515, 13506-900 Rio Claro, São Paulo, Brasil. Pesquisador do CNPq. 


\section{MATERIALS AND METHODS}

The $P$. strinatti specimens used in the karyotype analysis were collected in the cave Ressurgência das Areias in Iporanga, São Paulo, in April 1985.

Pseudonannolene tocaiensis, sp.n. was collected in the cave of Toca, Fazenda da Toca, Itirapina, São Paulo, in February and August 1985 and in June 1986.

Adult males were used for both the morphological and the cytogenetical analyses. For the chromosome study, the testicular vesicles of the two species were removed in physiological solution and put in a hypotonic solution of $\mathrm{KCl} 0.45 \%$. They were then fixed in different solutions: fixer I $(1.5 \mathrm{ml}$ of glacial acetic acid + $1.5 \mathrm{ml}$ ethanol $+2 \mathrm{ml}$ of distilled water); fixer II ( $2 \mathrm{ml}$ of glacial acetic acid $+2 \mathrm{ml}$ ethanol); fixer III (Carnoy I) and fixer IV (glacial acetic acid). After being fixed the testicular vesicles were squashed on slides which were then dried on a hot metallic plate and stained with orcein $1 \%$.

\section{RESULTS AND DISCUSSION}

\section{Pseudonannolene tocaiensis, sp.n.}

Figs 1-3

Holotype. Adult male (no. 132 in the collection). Brazil, São Paulo: Itirapina (Fazenda da Toca, Toca Cave), 27-VIII-1985, C.S. Fontanetti, A. Mesa and F.A.G. Mello leg. Paratypes: males and females, same locality 24-II-1985, A. Mesa and F.A.G. de Mello leg. (no. 18); 27-VII-1985; C.S. Fontanetti, A. Mesa and F.A.G. Mello leg. (no. 199-114); 18-VI-1986, C.S. Fontanetti, V.G. Martins and D.M. Cella leg. (no. 130-133); material deposited in the collection of the Department of Biology, Institute of Biosciences, UNESP/Rio Claro, São Paulo, Brazil.

Description. Long slender body, dark coloring (black) with head, colum and second segment clearer. Metazonite clearer than prozonites. The legs, antennae and edges of the anal valve clearer than the body.

Head with a groove on the vertex which goes beyond the frontal join. Long antennae heavily covered with fine bristles. Ocelli very distinct.

Metazonites of the same diameter as the prozonites, a little striated.

Anal valves without bristles.

The first pair of male legs (Fig. 1): coxa longer than wider, totally covered with bristles; coxa with a wide base, which narrows abruptly forming a step at the external side; the base of the coxa twice as wide as the distal portion. All the segments heavily covered with strong bristles. Small pre-femur, with a long process, parallel to its pair, covered with strong bristles.

Gonopods (Figs 2, 3). Large coxa, 1.5 times longer than the basal width, the internal part densely covered by small dentiform processes. Telopodite with wide base which narrows abruptly, forming a step; apical portion covered with thick bristles as far as the step; telopodite length approximately three times shorter than that of the coxa. Solenomorite larger than the telopodite, pointing upward and slightly outward; scaly distal part of same width as the basal portion. 

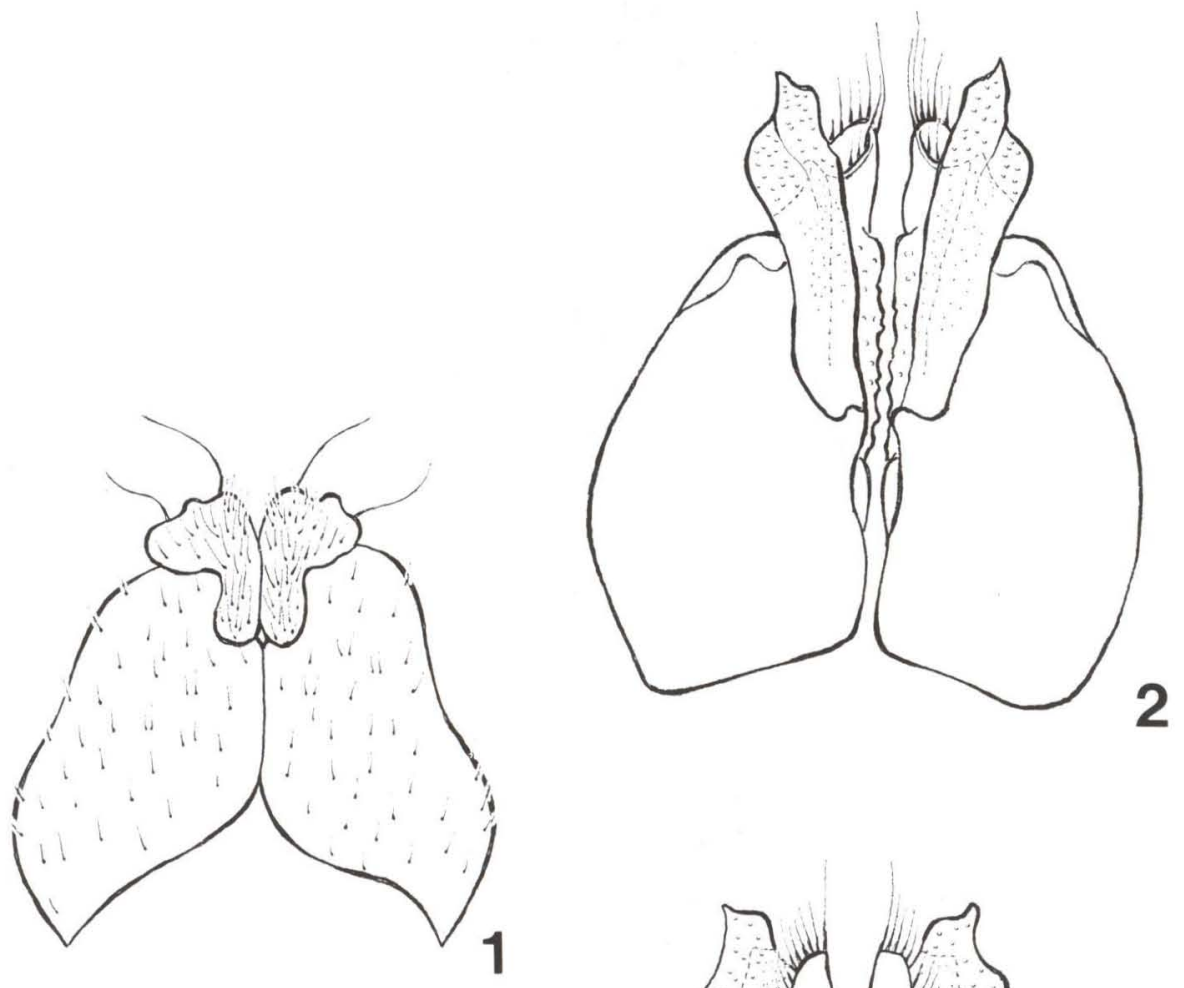

\section{$1 \mathrm{~mm}$}

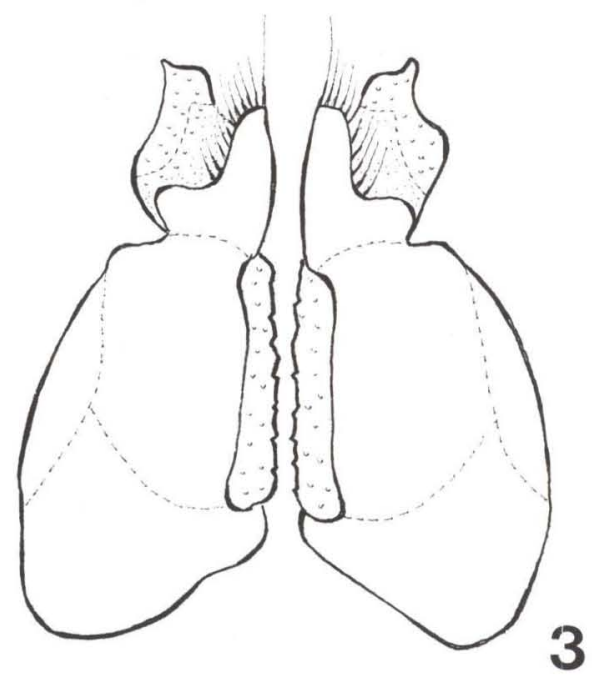

Figs 1-3. Pseudonannolene tocaiensis, sp.n.. (1) Oral view of the male first pair of legs; (2) oral view of the gonopods; (3) caudal view of the gonopods. 

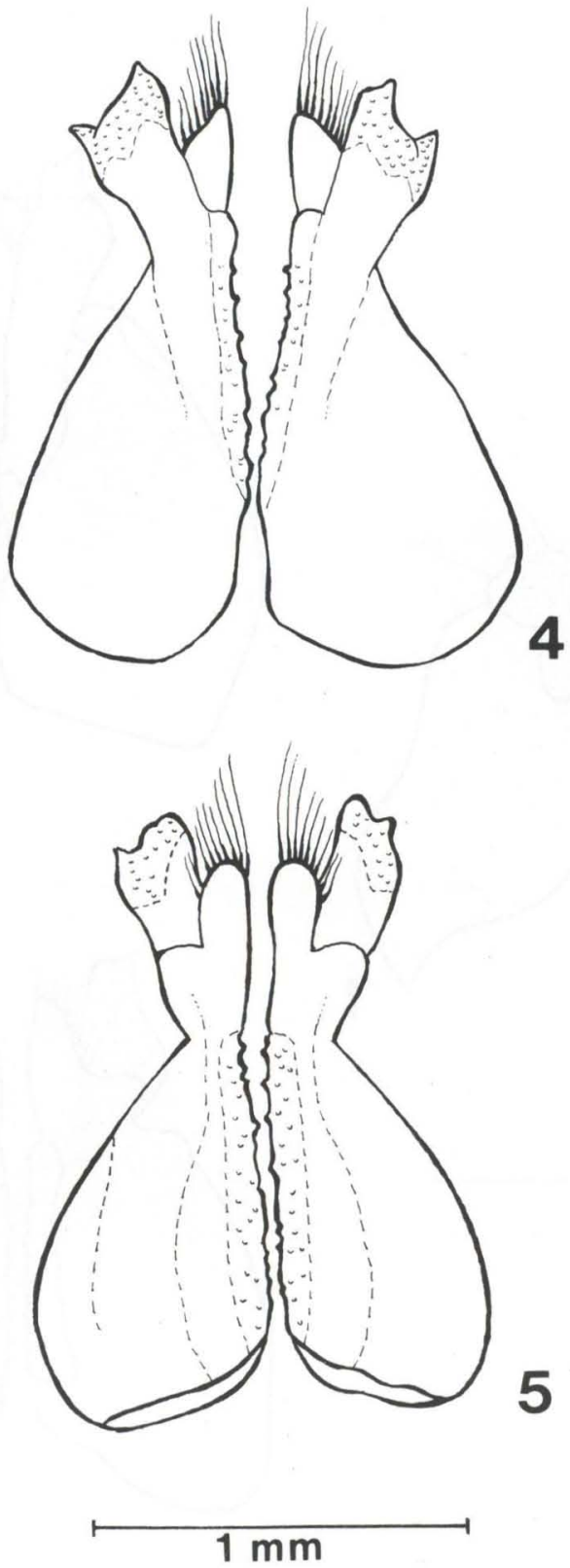

Figs 4-5. Pseudonannolene strinatii Mauriès, 1974. (4) Oral view of the gonopods; (5) caudal view of the gonopods. 


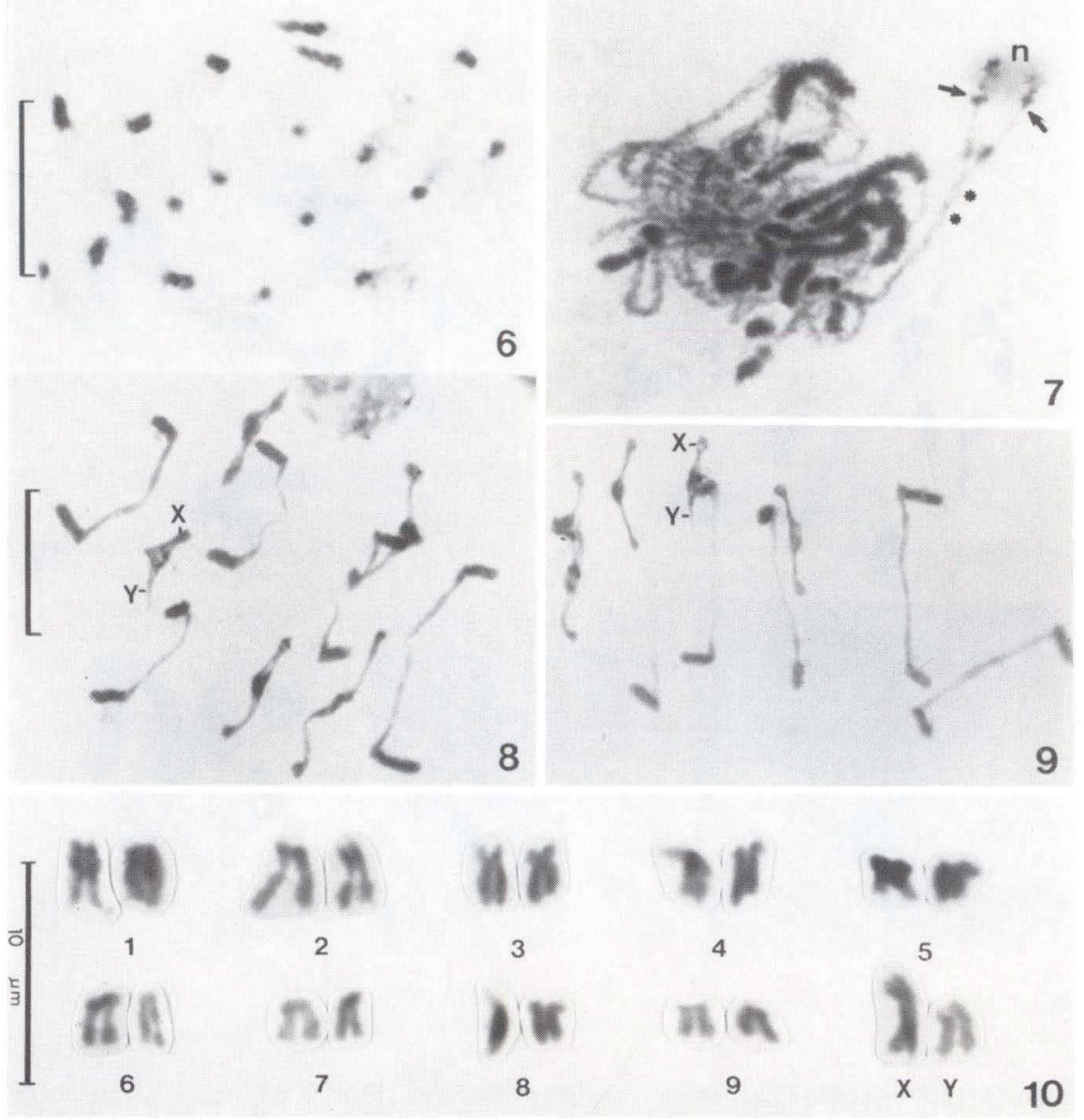

Figs 6-10. Meiosis of Pseudonannolene tocaiensis, sp.n. (6) Median prophase (part of the chromatin is diffuse); (7) zygotene, observe the nucleolus ( $n$ ) along with two chromosomes (arrows) and the pairing on the less condensed portion (*); (8-9) metaphase I; (10) karyotype mounted from the end of the anaphase I.

Discussion. The species differs from P.strinnatti (the only genus described for cave environments), in the dark coloring ( $P$. strinatti is lighter - brownish), in size $(P$. strinatti is larger and more robust) and in the setting of the gonopods (compare Figs 2, 3 with 4,5). P.strinatii only has bristles on the distal portion of the telopodite, the distal portion of the coxa is much narrower than the basal portion and the length of the telopodite is approximately two times shorter than the coxa.

Pseudonannolene tocaiensis, has $2 \mathrm{n}=20$, XY (Figs 6-10). The prophase follows the standard of the diplopods species studied up to now (FONTANETTI 1990); figure 6 shows the phase in which part of the chromatin goes through a diffused period and in figure 7, zygotene, the pairing carried out on the less condensed portion 


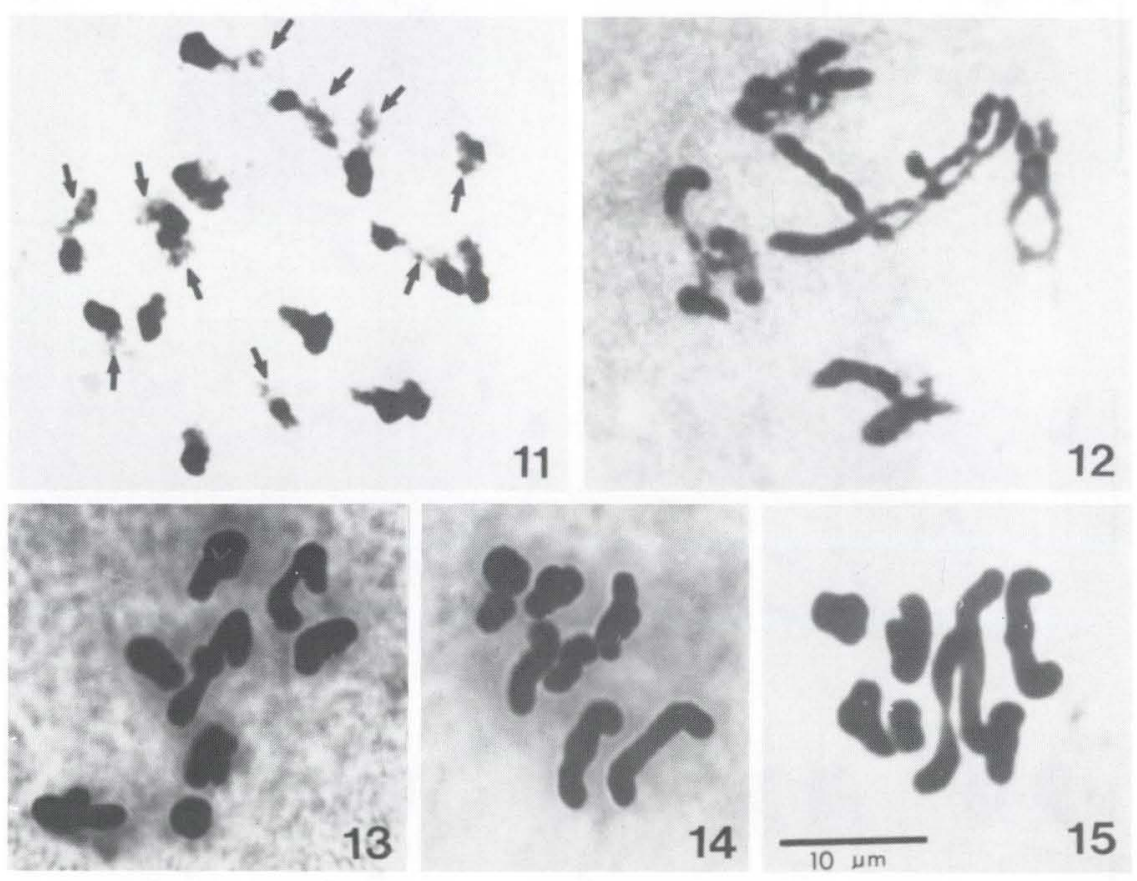

Figs 11-15. Meioses in Pseudonannolene strinatii Mauriès, 1974. (11) Phase in which part of the chromatin begins to condense back (arrows) after going through a diffuse stage; (12) diplotene; (13) pre-metaphase; (14-15) metaphase I.

of chromatin. The sexual pair in this species is easily detected by the size difference between the two elements and by the position of the centromere (Figs 8,9,10) which suggests that $\mathrm{Y}$ is acrocentric and that the $\mathrm{X}$ is metacentric or submetacentric. The chromosome morphology has not been confirmed, but several karyotypes it can be suggested that the pairs $1,3,5$ and 8 are metacentric or submetacentric and the pairs 2, 4, 6, 7 and 9 are acrocentric (Fig. 10).

From several collects it can be concluded that P.strinatii is widely distributed in caves of several Brazilian states (São Paulo, Minas Gerais, Paraná).

The species has $2 \mathrm{n}=16$ (Figs 11-15) not being possible the observation of the sexual determination mechanism. The prophase also follows the pattern proposed by FONTANETTI (1990) (Fig. 11 shows part of the chromatin condensing again (arrows) after a diffuse period). Figure 12 shows a diplotene where the clumping tendency of the chromosomes can be observed. This was also observed by authors 
in different species (CHOWDAIAH \& KANAKA 1969, 1974). No heteromorphism was observed in the complement to indicate which one is the sexual pair (see Figs 13, 14 and 15$)$.

The majority of the Diplopoda species have XY type as the mechanism of sexual determination. However, the great majority of the analyzed species shows little or no heteromorphism in the chromosomes of the sexual pair. ACHAR (1983), while studying Spirostreptus asthenes Pocock, 1892 commented that the sex determination mechanisms of the Diplopoda is in a primitive state, for in the majority of species the sexual chromosomes are little differentiated from the autosomes. This observation is in agreement with the studies of a variety of placentary mammals in which $\mathrm{X}$ and $\mathrm{Y}$ have evolved from a pair of autosomes without morphological differentiation. In the diplopods species studied up to now, the heteromorphic nature of this pair cannot be proved only by the meiotic chromosomes. In fact, no female chromosome (which proves the XY mechanism) has been seen up to now, because of the difficulties in the chromosomic preparations.

The chromosome number $2 \mathrm{n}=16$, found in $P$. strinatii, has also been reported in three other diplopod species: Polyxenus sp. (Sokoloff 1914). Cingalobolus bugnioni Carl, 1918 (ACHAR 1987) and Spirostreptus asthenes Pocock, 1892 (CHOWDAiaH \& KanaKa 1969; ACHAR 1983), and the number found in $P$. tocaiensis $(2 \mathrm{n}=20)$ has also been reported for the following species: Glomeris annulata Brandt, 1833 (BESSIÈRE 1948), Ktenostreptus sp. (CHOWDAIAH 1966) and K. costulatus Attems, 1913 (CHOWDAIAH \& KANAKA 1979).

ACKNOWLEDGEMENTS. I specially thank Drs. Alejo Mesa and Miriam M.O. Levada for their orientations, Drs. Doralice Maria Cella, Francisco A. G. de Mello and Vanderlei G. Martins for their help in collecting and Flávio Chaimowickz and Ricardo Pinto-da-Rocha for sending part of the material. I also thank CNPq and FAPESP for the financial support.

\section{REFERENCES}

ACHAR, K.P. 1983. The use of G-banding technique in the chromosome studies of a milliped species Spirostreptus asthenes. Current science 52 (11): 540-543. 1987. Chromosomal evolution in Diplopoda (Myriapoda: Arthropoda). Caryologia 40 (1-2): 145-155.

BESSIĖRE, C. 1948. La spermatogènese de quelques Myriapods diplopods. Arch. Zool. Exp. 85 (3): 149-236.

Chowdaiah, B.N. 1966. Cytological studies of some Indian Diplopoda (Myriapoda). Cytologia 31 (3): 294-301.

Chowdaiah, B.N. \& R. KanaKa. 1969. Cytological studies of Indian Diplopoda. II. (Myriapoda). Bull. Mus. Nat. D'Hist. Natur. 41 (2): 43-47.

1974. Cytological studies in six species of pill-millipedes (Diplopoda Myriapoda). Caryologia 27 (1): 55-64.

1979. Chromosome cytology of seven species of Indian Diplopoda (Myriapoda), p.9-20. In: M. CAMATTINI (Ed.). Myriapod Biology. Londres, 
Academic Press, 456p.

FontANETTI, C.S. 1990. Meiotic prophase in Diplopoda. Rev. Brasil. Genet. 13 (4): 697-703.

MAURIÈs, J.P. 1974. Um cambalidae cavernicole du Brésil, Pseudonannolene strinatii n.sp. (Myriapoda, Diplopoda). Rev. Suisse. Zool. 81 (2): 545-550.

SCHUBART, O. 1946. Primeira contribuição sobre os diplópodos cavernicolos do Brasil, p.307-314. In: Soc. Bras. Ent. (Ed.). Livro de Homenagem a R.F. d'Almeida. São Paulo, Sociedade Brasileira de Entomologia, XXIII+349p. 1956. Cryptodesmidae do litoral do Estado de São Paulo (Diplopoda, Proterospermophora). An. Acad. Bras. Ci. 28 (3): 373-386.

Sokoloff, J. 1914. Über die Spermatogenese bei Polyxenus sp. Zool. Anz. 44: 558-566.

Recebido em 30.XI.1995; aceito em 11.X.1996. 